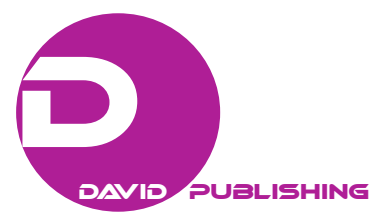

\title{
Gerontolinguistics and Its Prospect in the Health Care
}

\section{Industry in Shandong*}

\author{
Zhang Yan, Guo Yin \\ Qingdao University of Technology, Qingdao, China
}

\begin{abstract}
Gerontolinguistics is the combination of gerontology and linguistics, with the elderly language health as the core of its research. A brief investigation of the health care industry situation in Shandong province, China indicates that the government has provided political and financial support and wealthy practical resources for the application of gerontolinguistics, which in turn helps release the pressure caused by the increasingly serious problem of population aging. A thorough review of the academic research status and trends domestic and international shows that research on the language health of the elderly is underway, but not comprehensive enough. The paper suggests multidisciplinary collaboration to promote gerontolinguistics research and puts forward several recommendations in order to provide academic support for the elderly language health research and promote health care industry of Shandong and China.
\end{abstract}

Keywords: gerontolinguistics, aging society, elderly language health, health care industry

\section{Introduction}

Language is the most important means of communication and accordingly the elderly language health is one of the vital components of the elderly health care. China is the country with the largest total elderly population in the world, therefore responding actively to the aging population has become a major development strategy for the country. In China, Shandong Province is the one with the largest total elderly population, with an increasingly urgent need of elderly health care. It is reported that by the end of 2017, there has been more than 20 million people aged over 60, accounting for $21.4 \%$ of the total population in Shandong Province. Undoubtedly, elderly health care industry and researches related are necessary and promising. Some subjects, like pathology, epistemology, psychology, retirement of the elderly, have long been the focus of gerontology, while the well-being of the elderly's linguistic life is generally overlooked (Gu, 2019). Therefore, gerontolinguistics, a combination of gerontology and linguistics, should be taken into consideration as one of the theoretical and practical bases for the coping strategies for an aging society.

\section{The Policy Background of Health Care Industry}

The new and old kinetic energy conversion policy and the needs of the country's economy promote the development of health care industry in Shandong province.

\footnotetext{
*Acknowledgements: This paper was sponsored by 2019 Shandong Education Science Planning Project "A Study on the Predicament and Countermeasures of College English Education in China from the Perspective of Ecology of Education” (Item No.: BYGY201917).

Zhang Yan, M.A., associate professor, School of Humanities and Foreign Languages, Qingdao University of Technology.

Guo Yin, Ph.D., professor, School of Humanities and Foreign Languages, Qingdao University of Technology.
} 
The health care industry is one of the top 10 industries which the new and old kinetic energy conversion projects in Shandong province focus on and three cities are listed as national pilot units for the integration of medical and health care. General Secretary Xi Jinping has recently emphasized the need to strengthen scientific research on aging. Language health, which is closely related to the mental, physical, and pathological aspects of old age, should attract enough attention.

On January 10, 2018, the State Council formally approved to establish the Shandong New and Old Kinetic Energy Conversion Comprehensive Test Zone. This is the starting national development strategy after the party's 19th National Congress and the first regional development strategy in China with the theme of converting old and new kinetic energy. On February 22, 2018, the Shandong Provincial Party Committee of the Communist Party of China and the Shandong Provincial People's Government held a mobilization meeting discussing major projects for the conversion of old and new kinetic energy strategy. It is confirmed that we must focus on the 10 industries that represent Shandong's advantages and future development directions, that is, high-end equipment manufacturing, high-end chemical industry, information industry, energy raw materials, marine economy, modern agriculture, cultural industry, health care, tourism industry, modern finance, and to build the main carriers and leading forces of the strategy. The Comprehensive Test Zones of Shandong New and Old Kinetic Energy Conversion are located in the whole territory of Shandong, including the three core cities of Jinan, Qingdao, and Yantai, 14 national and provincial economic and technological development zones, high-tech industrial development zones, and special customs supervision areas of the district.

\section{Current Construction of Health Care Industry}

The Notice of the Shandong Provincial People's Government on Printing and Distributing the Implementation Plan for Major Projects of New and Old Kinetic Energy Conversion in Shandong Province (Shandong [2018] No. 7) (2018.2.23) decided to strongly support the ten major industries including the health care industry. By 2022, a new pattern will have been formed in which new kinetic energy will lead the development of the state-owned economy, and strive to achieve operating income of 1.6 trillion yuan for provincial-owned enterprises.

The current health care industry entities in Shandong are mainly represented in the following three categories. Details are as follows.

\section{Pharmaceutical Industry}

Jinan Life Science City, Qingdao Biomedical Industrial Park, International Biotechnology Park in Yantai Shandong, Oriental Marine Precision Medical Technology Park, Weifang Biomedical Technology Industrial

Park, Jining Biotechnology Industrial Base, Tai'an Taibang Biomedical Industrial Park, Linyi Luoxin Pharmaceutical Traditional Chinese Medicine Industrial Park, Zaozhuang China Resources Sanjiu Traditional Chinese Medicine Granule Industry Base, Medical Device and Biomedical Industrial Parks in Zibo and Weihai.

\section{Combination of Medical and Nursing}

Jinan International Medical Science Center, Zhangqiu District Eastern Medical Center health care base, Qingdao National Sports Industrial Park, Guoke Health Technology Town, East Aoshan Bay Future City, Yantai LekangJinyue Health Industrial Park, Luye Health City, Lotte Medical Health Industry Park, Southern Fushan Ecological New City, Zibo Medical and Health Innovation Park, Zaozhuang Medical and Nursing Integrated Demonstration Base, Huanghekou (Dongying) Ecological Wetland Integrated Medical and Nursing 
Demonstration Zone, Weifang Medical and Nursing Health Industrial City, Southwest Shandong (Jining) Intelligent Medical Center and Huanweishan Lake Health Care Medical Base.

\section{Pilot Demonstration Projects}

Jinan National Health and Medical Big Data Pilot City, National Electronic Health Card Pilot City, National Pilot City of Social TCM Medical Institution, Qingdao International Senior Health Care and Health Industry Pilot Zone, Laoshan Bay International Ecological Health City National Health Tourism Demonstration Base, National Comprehensive Reform Zone for Traditional Chinese Medicine, National Rehabilitation Assistive Device Pilot City, Yantai National Life Science Innovation Demonstration Zone, Weifang National Life Science Innovation Demonstration Zone, National Traditional Chinese Medicine Inheritance Innovation Project.

\section{Domestic Academic Research Status and Trends}

In recent years, some scholars have begun to realize the fact that China's problem of aging population is getting worse. As of the end of 2019, the population aged 60 and over was 253.88 million, accounting for $18.1 \%$, among which the population aged 65 and over was 176.03 million, accounting for $12.6 \%$ (Zhang, 2020). Compared with the end of 2018, the proportion of the elderly population continues to rise. According to the “Great Health Industry Blue Book: China’s Great Health Industry Development Report” jointly issued by the Chinese Academy of Social Sciences and other units, the number of elderly people aged 60 and over in China will reach approximately 484 million in 2050 , accounting for $34.1 \%$ of the total population. The total consumption of the elderly population may reach 61.26 trillion yuan. The authors searched on China National Knowledge Infrastructure with "language health" as the key words, but did not get any document. It could be inferred that despite the increasing attention of the elderly health care issues, the language health problems of the elderly, which are closely related to the psychology, physiology, and pathology of the elderly, have not attracted enough attention from all walks of life. There is still a certain gap between the current situation of language health of the elderly and the expectation of satisfactory life in old age. The current researches on language and the elderly mainly focus on the following aspects:

\section{Research on Linguistic Characteristics of the Elderly}

Cognitive aging and language understanding research, and language aging of special populations are the focus of language aging research in the past decade. Gu (2019) proposed that the research object of linguistics for the elderly makes the language of the elderly related to the negative growth phenomena of the body, the brain, and the heart, and it can be divided into four subcategories: linguistic, linguistic errors, eclipse, and language barrier. Lu and Chen (2018) proposed that targeted training methods for the problem of language erosion and language loss of the elderly through investigation and analysis and instrument detection, so as to reshape the social status of the elderly and reflect the social value of the elderly. Huang and Zhu (2019) suggested that it is necessary to conduct a comprehensive and in-depth study from the perspective of pragmatics to study the language aging problem of the elderly. $\mathrm{Wu}, \mathrm{Xu}, \mathrm{Gu}$, and Zhang (2014) conducted a study on the main features of clinical language use disorder in Alzheimer's dementia from the perspective of clinical linguistics by using the language use disorder evaluation parameter table. Luo and Peng (2001) discussed the current status and prospects of dementia language research, integrate the research results of Western countries in this field and introduce the main aspects of dementia language research (phoneme, syntax, 
semantics, discourse, and pragmatics) aspect. Y. Wang and J. Wang (1999) studied the changes and characteristics of language disorders in Alzheimer's disease (AD) at various stages. According to their research, the severity of dementia is the most important factor affecting $\mathrm{AD}$ language disorders and the language changes in early $\mathrm{AD}$ can be used as a basis for early diagnosis and differential diagnosis.

\section{Study of Linguistic Output of Old Age and Social Communication}

Cen and Liu (2008) examined the social characteristics of aging language through the phenomenon of language generation gap. Dong, Zhang, Yang, and Zhao (2017) researched and investigated the comprehensive assessment algorithm of language communication ability of the elderly to provide a basis for graded care and nursing. Li and Zhu (2018) investigated the three dimensions of language use, mandarin level, and dialect use. According to the current situation of Chinese elderly's use of language codes and its influencing factors, it is found that due to the characteristics of the times, the elderly are mostly not good at foreign languages, and about 1/3 are not good at mandarin. Huang and Pan (2018) discussed the language preference of middle-aged and elderly people, basing on the use of expression packs by middle-aged and elderly people on social media. Zhan and Pu (2010) focused on how to use and protect language resources in the context of an aging population, maximize the reasonable distribution of language resources, build a harmonious language life, and reflect social equity.

\section{Nursing Intervention Study of Language Disorders in the Elderly}

Bai, Zhai, Yuan, and Zhao (2017) conducted cognitive intervention on elderly stroke aphasia patients on the basis of speech training, and find that it can effectively improve patients' cognitive dysfunction and language function and improve their quality of life. Xu (2016) observed the rehabilitation effect of comprehensive nursing intervention for patients with stroke aphasia, and find that the observation group's total recovery of language ability after nursing is significantly better than the control group. Comprehensive nursing intervention has a significant promotion effect on the rehabilitation of stroke aphasia patients. Wu (2014) found that psychological care and social support can effectively improve the language ability and life ability of patients with dementia and improve the quality of life of patients. The effects of psychological care and social support intervention on the living ability and language ability of Alzheimer's patients are discussed. The study of Liu (2018) shown that nursing intervention based on the health belief model can help improve the language ability and cognitive function of Alzheimer's patients. Zhang (2016) implemented holistic rehabilitation nursing for elderly stroke aphasia patients, grasped the timing of language training, and found that it is effective to help aphasia patients to recover language function.

\section{Research on Elderly Language Nursing and Companionship Strategy}

It mainly includes the application of verbal and non-verbal communication in nursing care of elderly patients. The researchers believe that the use of language communication skills in the care of elderly patients can promote the improvement of patients' psychological emotions, improve compliance with doctors, the quality of life of patients, the quality of clinical services, patient satisfaction, and reduce physical therapy disputes (Zeng, 2019; Liu, 2016; Wang, 2013). Proper language communication can make the elderly patients in the best recovery state during the treatment and care, promote the relationship between nursing staff and elderly patients, and improve the nursing satisfaction of elderly patients (Bai, Liu, Zheng, \& Yang, 2019). Studies have shown that the introduction of body language communication mode in the outpatient care of elderly patients can improve the patient's nursing acceptance rate and nursing satisfaction (Wang, 2019). In the 
communication with elderly patients, non-verbal communication is attractive and more contagious than verbal communication due to its expressive power (Zhu, 2014). Zeng (2018) used artificial intelligence technology to design service robots for senior care issues, and provided language care services for the elderly through speech recognition and synthesis, natural language processing, image recognition and understanding, communication and navigation, and other technologies.

It can be inferred from the literature above that most of the researches concerning the elderly and language focus on dementia language research and nursing of the sick elderly, the Alzheimer's patients in particular, with the abnormal aging group as the subject. However, gerontolinguistics study should also cover other three elderly groups, that is, the super fit, the successful and the normal aging groups. Therefore, further exploration is needed to cover the whole group of the elderly. In addition, the application of gerontolinguistics in elderly education and care is rare.

\section{International Research Status and Trends}

In the past 30 years, foreign studies on the language ability of the elderly have successively appeared in some research literature. The following aspects of the studies are especially worthy of our reference.

\section{The Elderly's Language Ability Training and Nursing}

Some have proposed the exploratory application of the principle of critical geragogy in foreign language education, which takes into account the characteristics of the elderly, effectively reduces the self-frustration of the elderly foreign language learners, helps to improve the self-expectation and goal setting of the elderly in language learning, and ensures the final learning achievement. In order to develop critical geragogy, Fomosa (2002) integrated critical geragogy within a praxeological epistemology as a continual reconstruction of thought and action in the lived experience of older people, brings together critical reflective processes with actual experiences, and offers more workable principles for the practice of critical geragogy. Murray (2011) explored the topic of designing learning opportunities for older learners outside of the classroom context and suggested that Language educators and researchers should turn their attention to the matter of learning languages later in life and the challenges older learners face. Some researchers (Eguz, 2019; Stickney \& Vilshanskaya, 2005) investigated the benefits and challenges brought by engaging the elderly into learning a second language.

Many researchers concentrate on the language changes and communication skills of Alzheimer's patients, analyze the impact of deterioration of language and cognition on the ability of holding a conversation and its negative effect on social interaction, and report cognitive interventions focused on the language and communication of the patients as therapy without use of medication (Cruze, Machado, \& Lenisa, 2019).

\section{The Aging Language Dementia Assessment Scale and Localization}

The birth rate and mortality rate of newborn children in developed countries are low, leading to an increasingly serious problem of aging. Researchers are aware of the importance of early assessment and screening of dementia patients. At present, the Montreal Cognitive Assessment Scale (MoCA) and the Dementia Knowledge Assessment Scale (DKAS) are among the internationally recognized scales with accepted reliability and validity. Because these two scales are mainly set in English-speaking countries, researchers of non-English-speaking countries are trying to localize them to screen for Parkinson's disease and dementia patients. For instance, Annear, Otani, and Li (2017) developed and verified a Japanese translation of the DKAS 
to address the paucity of reliable and valid Japanese-language measures and to elucidate current understanding.

\section{The Multi-Dimensional Study of Gerontolinguistics}

It mainly focuses on the similarities and differences between the languages of different age groups, language variation in different social or cultural backgrounds, and the identity of the elderly. Lütjen (1978) presented that the search for the felicity conditions of verbal interaction among members of different age groups is called "etatolinguistics" and "gerontolinguistics", if older people are involved in the verbal interactions to be investigated. Heike, Evans, and Ashley (2018) investigated the differences and changes of aging language in the context of ageism, provided linguists with an overview of relevant conceptualizations of age and ageing in gerontology, explain why a focus on older speakers is critical to the advancement of the study of language variation and change, and offered practical suggestions for overcoming some of the challenges associated with old-age research. Makoni (2007) analyzed gerontolinguistics in South Africa and characterizes discourses in caring institutions in South Africa and the United Kingdom from the perspective of comparative gerontolinguistics (Makoni \& Grainger, 2002). Wang, Xiao, Yan, Wang, and Yasheng (2018) took the Xinjiang region of China as an example to conduct a study on the cultural abilities of multicultural and nursing students in elderly care in developing regions. García, Flores, Spotti, and Makoni (2017) investigated African cultural practices from an aging perspective and drew on African languages by analyzing aging in institutional contexts, aging and gender, care in institutional settings, and elder speak in relation to urban vernaculars. Based on social constructionist phenomenology, Jen's (2018) study explored the gender identity of transgender and gender non-conforming older adults and report's findings from a Foucauldian discourse analysis of interviews with two older women who had previously undergone sexual reassignment or gender confirmation surgery.

On the whole, there are not sufficient multidisciplinary researches on the linguistic, physiological, psychological, and social diversity of the elderly.

\section{Multidisciplinary Collaboration to Promote Gerontolinguistics Research}

The problem of population aging is a major social problem that has been highlighted along with the urbanization process in China. In recent years, the State Council has issued guidance documents, such as "Several Opinions on Accelerating the Development of the Elderly Service Industry" and "Several Opinions on Promoting the Development of the Health Service Industry," and gradually formed the top-level design of the health and elderly service industry in China. The support of the government provides a favorable policy environment and brings major strategic opportunities for the development of health care industry and research in gerontolinguistics. The rapid development of medical and health industry demands the application of academic theory which will further promote the academic research.

In this context, exploration of the language loss process, communication and cognitive characteristics of the elderly group, early diagnosis and research of language loss-related diseases, treatment, and care, mechanisms of recession and influencing factors, pursuit of a better life for the elderly, and basic researches of building a healthy nation are all the strategic needs to cope with an aging society and the necessary ways of the development of the health care industry. National development blueprint makes it clear that we should implement a healthy-China strategy, actively respond to the aging population, and accelerate the development of undertakings and industries for the elderly. At present, research on the language health of the elderly is underway, although it is not comprehensive enough. We believe that the following aspects need to be further 
expanded in order to obtain theoretical and practical breakthroughs in this field.

\section{Discipline Status and Application of Gerontolinguistics}

First, we should establish the discipline status of gerontolinguistics (or linguistics of ageing) and apply its theory to the practice of linguistic medical health care and diagnosis and treatment for the elderly. Gerontolinguistics, as the name implies, is about the language problems of the elderly. If the subject is categorized, it should span two disciplines, namely, gerontology and linguistics. However, there are few academic works on gerontolinguistics currently. Checking China National Knowledge Infrastructure (CNKI) with gerontolinguistics as the theme, we have found only nine academic works, and the works conducted by Chinese scholars are all published after 2019. It can be seen that gerentolinguistics has not yet become a recognized branch of linguistics in China, even around the world. For many years, gerontology has been focusing on geriatric medicine, geriatric sociology, etc. The linguistic issues of the elderly have not yet entered the views of most researchers. Fortunately, people of insight in the academic circles have realized the importance of this issue, and advocated the establishment of a number of specialized research institutions. For example, Professor Gu Yueguo of the Chinese Academy of Social Sciences and Associate Professor Huang Lihe of the School of Foreign Languages of Tongji University have established Tongji University Research Center on Aging Language and Nursing. Professor Ma Wen of Shandong University leads the Nursing Research Center and the Experimental Center for Neurolinguistics and Language Disorder Research of Shandong University. Basing on their academic works, these researchers are appealing in many ways to establish the discipline status of gerontolinguistics as soon as possible.

\section{Two-Way Relationship Between Psychological Care and Language Care of the Elderly}

Second, a two-way relationship between psychological care and language care of the elderly should be established. It is generally believed that psychological care and social support can promote the improvement of language ability, and the two forms a unidirectional derivative relationship. In fact, the two interact mutually. Reasonable language care can also bring positive psychological reflections of the elderly, thus promoting the psychological care.

\section{Exploration of the Erosion Phenomena and Development Laws of Elderly Languages}

Third, we should explore the erosion phenomena and development laws of elderly languages in terms of pronunciation, intonation, vocabulary selection, sentence changes, rhetorical diversity, tone, language attitude, etc. by combining quantitative and qualitative methods. In addition, the following researches should be strengthened, that is, the typical and a typical research on the linguistic features of aging language, the neural mechanism research on the elderly speech understanding and output, and research on the early warning mechanism of brain diseases based on artificial intelligence. Furthermore, predictions about geriatric depression and Alzheimer's disease could help relieve the disease through the intervention of language care as soon as possible.

\section{Provision of Basic Data}

Fourth, the data format and detection dimensions of early screening for language dementia should be improved. For instance, we may develop and verify a Chinese translation of the DKAS to alleviate the lack of reliable and valid Chinese-language measures. The provision of basic data may provide reliable reference for the construction of healthy aging cities and towns in Shandong, China and contribute to the well-being of the 
elderly’s linguistic life.

\section{Conclusion}

The problem of population aging is a major social problem that has been highlighted along with the urbanization process in China. The report of the 19th National Congress of the Communist Party of China clearly states that a healthy China strategy should be implemented to actively respond to the aging of the population and accelerate the development of aging undertakings and industries. Gerontolinguistics, the study on elderly language health, could assist the implementation of the national and provincial strategies, actively serve the development of the aging undertakings and industries in Shandong and China, bring great benefits to the elderly, and make due contributions to the decisive victory of our country in building a well-off society in an all-round way. It may be predicted that gerontolingustics will have a wide application and a promising prospect in Shandong, and in China.

\section{Recommendations}

In the implementation process of gerontolinguistics research, the following recommendations could be made.

1. It is recommended that more specialized research institutes should be established which could combine the academic units and social entities. Universities and colleges may take advantage of their resources, such as academic researchers, off-campus practice bases (nursing homes, hospitals, ect.), and psychological counseling centers, to carry out academic research and social practice and application;

2. As for the research content, it should cover different manifestations of language aging (normal language aging and rapid language aging) in order to make predictions for special lesions. It should also improve the language proficiency assessment system to provide an important reference for cognitive ability assessment;

3. The key issue to be solved currently is the theoretical review of gerontolinguistics. It has just emerged in China and its international academic status is still unstable. The theoretical literature of gerontolinguistics in different international and geographical regions of the East and the West should be sorted out and reviewed;

4. It is recommended that multiple methods should be adopted in research, such as corpus research method (e.g., multimodal database), case analysis, combination of quantitative and qualitative methods, etc.

\section{References}

Annear, M. J., Otani, J., \& Li, J. (2017). Japanese-language dementia knowledge assessment scale: Psychometric performance, and health student and professional understanding. Geriatrics \& Gerontology International, 17, 1746-1751.

Bai, J., Zhai, L. L., Yuan, J. M., \& Zhao, S. H. (2017). The effect of cognitive intervention based on speech training on language function and quality of life in elderly patients with stroke aphasia. Chinese Journal of Practical Nervous Diseases, 20(2), 55-57.

Bai, Y. L, Liu, X., Zheng, Y., \& Yang, Y. (2019). Application of six-step standard communication process in nursing communication with elderly lung cancer patients. Chinese Journal of Modern Nursing, 19, 2475-2479.

Cen, Y. Q., \& Liu, A. M. (2008). Don’t we have a common language? On generation gap of speech. Yuwen Jianshe, 3, 55-57.

Cruz, M. A. N. D., Machado, L. T., \& Lenisa, B. (2017). Language and communication non-pharmacological interventions in patients with Alzheimer's disease: A systematic review-Communication intervention in Alzheimer. Dementia \& Neuropsychologia, 11(3), 227-241.

Dong, Y., Zhang, X. L., Yang, P., \& Zhao, M. (2017). Evaluation of verbal communication ability in old people: An algorithm based on fuzzy principal component. Chinese Journal of Rehabilitation Theory and Practice, 23(11), 1346-1350. 
Eguz, E. (2019). Learning a second language in late adulthood: benefits and challenges. Educational Gerontology, 45(12), 701-707.

Formosa, M. (2002). Critical geragogy: Developing practical possibilities for critical educational gerontology. Education \& Ageing, 17, 73-85.

García, O., Flores, N., Spotti, M., \& Makoni, S. (2017, January 5). From elder speak to gerontolinguistics: Sociolinguistic myths. In The Oxford Handbook of Language and Society. Oxford: Oxford University Press. Retrieved May 5, 2020, from https://www.oxfordhandbooks.com/view/10.1093/oxfordhb/9780190212896.001.0001/oxfordhb-9780190212896-e-19

Gu, Y. G. (2019). Exploring gerontolinguistics. Chinese Journal of Language Policy and Planning, 4(5), 12-33.

Heike, P., Evans, W. S., \& Ashley, H. (2018). Old-age language variation and change: confronting variationist ageism. Language \& Linguistics Compass, 12(6), e12281.

Huang, L. H., \& Zhu, Q. (2019). Pragmatic studies in gerontolinguistics: Perspectives, methods and topics. Journal of East China Normal University (Humanities and Social Sciences), 51(6), 129-137.

Huang, Z. J., \& Pan, L. L. (2018). Group identity separation in cyberspace from middle-aged and elderly expression packs. Modern Communication, 40(4), 97-102.

Jen, S. (2018). Discourses of gender identity and transition in later life. Journal of Research on Women and Gender, 8, 49-64.

Li, Y. F., \& Zhu, N. (2018). The current status of code using among the elderly and its influencing factors. Journal of Northeast Normal University, 6, 77-81.

Liu, D. L. (2018). The effect of nursing intervention based on health belief model on language ability and cognitive function of Alzheimer's patients. Health Way, 7, 128.

Liu, F. (2016). On the importance of language communication skills in nursing elderly patients. Tibet’s Science \& Technology, 11, 60.

Lu, L., \& Chen, H. Y. (2018). Influencing factors in aged people’s language loss and training methods. Journal of Jilin Engineering Normal University, 34(8), 62-64.

Luo, Q., \& Peng, D. L. (2001). A linguistic perspective on dementia. Contemporary Linguistics, 2,109-118.

Lütjen, H. P. (1978). Linguistics of ageing, linguistic gerontology—Why? (The author's translation). Aktuelle Gerontologie, 8(6), 331-336.

Makoni, S., \& Grainger, K. (2002). Comparative gerontolinguistics: Characterizing discourses in caring institutions in South Africa and the United Kingdom. Journal of Social Issues, 4(58), 805-824.

Makoni, S. (2007). Gerontolinguistics in South Africa. International Journal of Applied Linguistics, 7(1), 57-65.

Murray, G. (2011). Older language learners, social learning spaces, and community. In P. Benson and H. Reinders (Eds.), Beyond the language classroom (pp. 132-145). UK: Palgrave Macmillan.

Stickney, B., \& Vilshanskaya, O. (2005). Engaging older people with English as a second language and frail older people in physical activity. Health Promotion Journal of Australia, 16(2), 116-123.

The Notice of the Shandong Provincial People’s Government on Printing and Distributing the Implementation Plan for Major Projects of New and Old Kinetic Energy Conversion in Shandong Province (Shandong [2018] No. 7). Retrieved May 3, 2020, from http://zwfw.sd.gov.cn/art/2018/2/23/art_1684_1455.html

Wang, L. (2019). Application of body language communication in outpatient nursing of elderly patients. China Continuing Medical Education, 11(31), 180-182.

Wang, Y. H., \& Wang, J. (1999). Study on language disorders in Alzheimer disease. Gereatrics \& Health Care, $4,60-163$.

Wang, Y. F. (2013). Analysis of application effect of language communication in nursing of elderly patients. Guide of China Medicine, 11(10), 707-708.

Wang, Y. R., Xiao D. X., Yan, P., Wang Y., \& Yasheng, A. (2018). Nursing students' cultural competence in caring for older people in a multicultural and developing region. Nurse Education Today, 70, 47-53.

Wu, G. L, Xu, X. F., Gu, Y. G., \& Zhang, Y. W. (2014). Frameworks in researching language impairments in ad patients. Contemporary Linguistics, 16(4), 452-465.

$\mathrm{Wu}, \mathrm{J}$. (2014). The effects of psychological nursing and social support on the ability to live a normal life of senile dementia patients. Health Research, 34(6), 654-655.

$\mathrm{Xu}$, D. (2016). Observation on rehabilitation effect of comprehensive nursing intervention for patients with stroke aphasia. Family Nurse, 14(16), 1664-1666.

Zeng, M. C. (2018). The design of the pension service robot based on artificial intelligence technology. Practical Electronics, 24, 21-22. 
Zeng, Y. J., Luo, L. Q., Li, R. D., \& Wu, J. Z. (2019). Analysis of the effect of the application of language communication in the nursing of elderly patients. Capital Medicine, 6, 93-94.

Zhan, J., \& Piao, Y. (2010). The ethical concern in the allocation of language resources in an elderly society. Nanjing Journal of Social Sciences, 11, 134-139.

Zhang, J. Z. (2016). Analysis of the effect of the application of language communication in the nursing of elderly patients. Journal of Clinical Psychosomatic Diseases, 22(S1), 391.

Zhang, Y. (2020). Population growth slows down, and urbanization continues to increase. Retrieved May 3, 2020, from http://www.stats.gov.cn/tjsj/sjjd/202001/t20200119_1723861.html

Zhu, Y. (2014). Application skills of nonverbal communication in elderly patients. Chinese Journal of Trauma and Disability Medicine, 22(3), 290-291.

2018 China Aging Health Report. (2018). Healthy aging is the only way to actively respond to population aging. Retrieved May 3, 2020, from http://www.360doc.com/content/19/0201/15/9793414_812548460.shtml 